\title{
Standards for thyroid laboratory testing, and cognitive functions after menopause
}

\author{
Iwona Bojar ${ }^{1}$, Przemysław Bejga², Mariusz Witczak², Robert Łyszcz ${ }^{1}$, Marta Makara-Studzinska ${ }^{3}$ \\ ${ }^{1}$ Department for Health Problems of Ageing, Institute of Rural Health in Lublin, Poland \\ ${ }^{2}$ College of Public Health, Zielona Góra, Poland \\ ${ }^{3}$ Department of Applied Psychology, Medical University of Lublin, Poland
}

\begin{abstract}
Introduction: The aim of the study is to analyze the relationship between normative and non-normative thyroid tests (TSH, TT4, TT3, FT3, FT4, anti-TPO, anti-Tg, AB-TSHR) and the level of cognitive functions in postmenopausal women.

Material and methods: The study group consisted of 383 women from south-eastern Poland, aged 50-65 years. The cognitive functions were evaluated using a diagnostic instrument - Central Nervous System - Vital Signs (CNS-VS). Blood was collected for determination of the following parameters: TSH, TT4, TT3, FT3, FT4, anti-TPO, anti-Tg, AB-TSHR.

Results: There were significant differences in $\mathrm{NCl}$, executive functions, psychomotor speed, reaction time, complex attention and cognitive flexibility, depending on the normative and non-normative level of TSH. Women whose level of FT3 was at the lower limit of the normal range obtained poorer results in psychomotor speed, while subjects with levels of FT4 below the standard achieved significantly lower scores for this function. The relationship between $\mathrm{NCl}$ and cognitive functions, and the normative and non-normative anti-TPO results, showed significant differences in verbal memory, visual memory, processing speed and reaction time. The level of AB-TSHR reported as normal or above the norm significantly differentiated from the results of $\mathrm{NCl}$, processing speed, executive functions, psychomotor speed, complex attention and cognitive flexibility.

Conclusions: Concentrations of laboratory parameters assessing the thyroid function located within the upper limits of the normal range showed a different relationship with the cognitive performance than concentrations located within the lower limits of the standard.
\end{abstract}

Key words: thyroid testing, cognitive dysfunction, menopausal age.

\section{Introduction}

Both hyperthyroidism and hypothyroidism can cause cognitive dysfunction by affecting the functions of the central nervous system. The issues of cognitive impairment in thyroid disorders are significantly less well-understood and are currently the subject of many studies. Complex attention, response speed, data processing and memory disorders were observed in the case of thyroid hormone dysfunction $[1,2]$.

Depression is one of the most frequently reported mental disorders associated with dysfunction of the thyroid gland. A fully developed form of the disease or a subclinical form is more common in patients with hypothyroidism, but may also appear in patients with hyperthyroidism [3]. A full-blown depressive syndrome can be observed in $50 \%$ of patients with hypothyroidism.

Bipolar disorders are also reported in the course of thyroid function disorders. Complaints of abnormal psychological well-being in patients with hypothyroidism may precede other symptoms. Anxiety is a mental disorder associated with hypothyroidism, which occurs in approximately $30 \%$ of patients with this disease.

The incidence of cognitive impairment in hyperthyroidism is lower than in hypothyroidism [4]. Neuropsychological testing performed in patients with hyperthyroidism indicated attention disorders, especially problems with concentration, fresh memory and executive functions $[3,5,6]$.

Cognitive impairment in patients with thyroid dysfunction is probably related to the malfunction of the neurotransmitter systems in the brain: dopaminergic, noradrenergic and serotonergic [7]. The relationship is emphasized between the impaired secretion of thyroid hormones, disturbed function of the neurotransmitter systems, depression and cognitive impairment [1].

\section{Study objective}

The analysis of the relationship between the normative (low, medium and high standard) and non-nor- 
mative thyroid tests (TSH, TT4, TT3, FT3, FT4, anti-TPO, anti-Tg, AB-TSHR), and the level of cognitive functions in postmenopausal women.

\section{Material and methods}

\section{Material}

The study was conducted in 2011 and 2012 at the Institute of Rural Health in Lublin. The study group comprised women from south-eastern Poland. The criteria of inclusion in the study were as follows: age 50-65, good general health, at least elementary education level. The women were also qualified into the study group based on clinical symptoms - minimum 2 years from the last menstrual period. The criteria for exclusion from the study were as follows: active cancerous disease within a period of five years before recruitment; mental diseases in medical history, including depression before menopause; addiction to drugs or alcohol; diagnosed nosologic unit with symptoms of dementia. At the stage of qualification for the study a brief Montreal Cognitive Assessment scale was conducted in order to include patients who did not show features of dementia [8]. The Montreal Cognitive Assessment scale for the evaluation of cognitive functions was designed as a quick screening instrument for the evaluation of mild cognitive dysfunctions, with a Polish adaptation of the scale by Magierska et al. The maximum score in this test is 30; and results of 26 or more are considered normal. All the women included in the study obtained more than 26 in the MoCA test.

\section{Neuropsychological assessment}

Cognitive functions were evaluated using the diagnostic instrument - Central Nervous System - Vital Signs (CNS-VS) (Polish version) [9] with software by CNS Vital Signs (1829 East Franklin St., Bldg. 500, Chapel Hill, NC 27514, USA). The instrument, in the form of a battery of computer tests, is standardized, has been subjected to the full validation procedure, and has a Polish adaptation. The entire research procedure with the use of a computer was performed in Polish. The report concerning test results is published in English. CNS-VS covers the following tests: Verbal Memory Test - VBM, a test examining motor function - Finger Tapping Test - FTT, the Symbol Digit Modalities Test SDMT, the Stroop Test - ST, the Shifting Attention Test SAT, and the Continuous Performance. CNS-VS assesses nine cognitive functions: memory, verbal memory, visual memory, processing speed, executive functions, psychomotor speed, reaction time, complex attention, and cognitive flexibility. Based on five of these functions: memory, psychomotor speed, reaction time, complex attention, and cognitive flexibility, the Neurocognitive Index $(\mathrm{NCl})$ is calculated. The computer data from the
CNS-VS test provide: raw results, standardized results, percentiles, and evaluations according to the 5-point scale for each of the nine cognitive functions examined and the Neurocognitive Index. These evaluations are as follows: above average (more than 109 standardized points), average (90-109), below average (80-89), low (70-79), or very low (less than 70).

\section{Laboratory tests}

Blood was collected for determination of the following parameters: TSH, TT4, TT3, FT3, FT4, anti-TPO, antiTg, AB-TSHR. The samples were immediately sent to the laboratory. The determinations were performed in the accredited laboratory SYNEVO.

Standards of the considered tests for postmenopausal women: TSH: 0.27-4.4 mU/l; TT4: 66-181 nmol/l; TT3: 1.3-3.1 nmol/l; FT4: 12-22 pmol/l; FT3: 3.1-6.8 pmol/l; Anti-TPO: 0-34 IU/l; Anti-Tg: 0-115 IU/l; AB-TSHR: 0-15 IU/I (SYNEVO 2011).

The thyroid tests were analyzed at the intervals of laboratory standards (below the norm, normal, above the norm). Due to a large number of women with normal characteristics of the thyroid gland, the normal range was divided into three sub-intervals of equal span; for the purposes of this study they were called as follows: low standard, middle standard and high standard.

\section{Statistical analysis}

The tables show the absolute $(n)$ and relative (the ratio of the number of units of a given variant of characteristics to the sample size, expressed in \%) numbers, minimum and maximum values, arithmetic mean $(M)$ reflecting the average level, and standard deviation (SD) measuring the degree of dispersion of measurements around the arithmetic mean, results of the regression analysis, as well as empirical values of statistical tests and the critical significance level $p$. It is the lowest - given the data results of a test - significance level at which the null hypothesis can be rejected.

Mean and standard deviation were calculated for $\mathrm{NCl}$ and 9 cognitive functions (in points) according to the characteristics of the thyroid in the laboratory test standards; the comparison used the $t$ test of the difference between paired values (for two compartments of laboratory ranges) and analysis of the variance $F$ test (for more than two laboratory ranges).

If the null hypothesis was rejected, no significant difference between the cognitive function results and laboratory standard compartments was indicated by multiple comparison tests (the least significant difference).

The graphs illustrate only the significant relationships between $\mathrm{NCl}$, the 9 cognitive functions, and the characteristics of the thyroid gland. 
The sample size was 383. Due to the large sample size, the critical normal distributions of estimates were accepted for the parameters.

The statistical tests were accepted at a level of significance of 0.05 .

\section{Results}

Nine cognitive functions and the neurocognitive in dex were evaluated using the CNS-VS test in the tested women. The women obtained the result of the Neurocognitive Index at a level of 84.4 points on average. This proved a below average overall assessment of the cognitive functions. The worst results were achieved in the tests for cognitive flexibility (78.64 points on average), processing speed (79.25 points on average), and executive functions ( 79.75 points on average). This indicates a poor assessment of cognitive functions. The patients scored slightly better in the tests for complex attention (82.24 points on average), psychomotor speed (83.42 points on average), and, even better, reaction time (86.87 points on average). This indicates below average evaluations of these cognitive functions. The tested women scored highest in the tests for memory $(90.15$ points on average), including verbal memory (91.22 points on average) and visual memory (93.37 points on average).

The results of $\mathrm{NCl}$ and cognitive functions (in points) were analyzed in the tested women, depending on the level of TSH, in three intervals of the standard (low, middle and high) and above the norm. Significant differences were observed in $\mathrm{NCl}$, executive functions, psychomotor speed, reaction time, complex attention and cognitive flexibility, depending on the normative and non-normative TSH level (Table I, Fig. 1).
Women with the low TSH standard compared to women with the high standard had better results in $\mathrm{NCl}$ (86.75 points on average - assessment below the average vs. 77.67 points - poor score), executive functions (83.63 points on average - assessment below the average vs. 67.69 points - very poor assessment), psychomotor speed (85.68 points on average - assessment below the average vs. 79.57 points - poor assessment), complex attention (86.20 points - assessment below the average vs. 67.43 points - very poor assessment) and cognitive flexibility (82.40 points on average - assessment below the average vs. 66.26 points - very poor assessment). Subjects with the high TSH standard had a lower performance of these functions than women with TSH above the norm, who were found to be below the average evaluation of $\mathrm{NCl}$ (84.61 points on average),

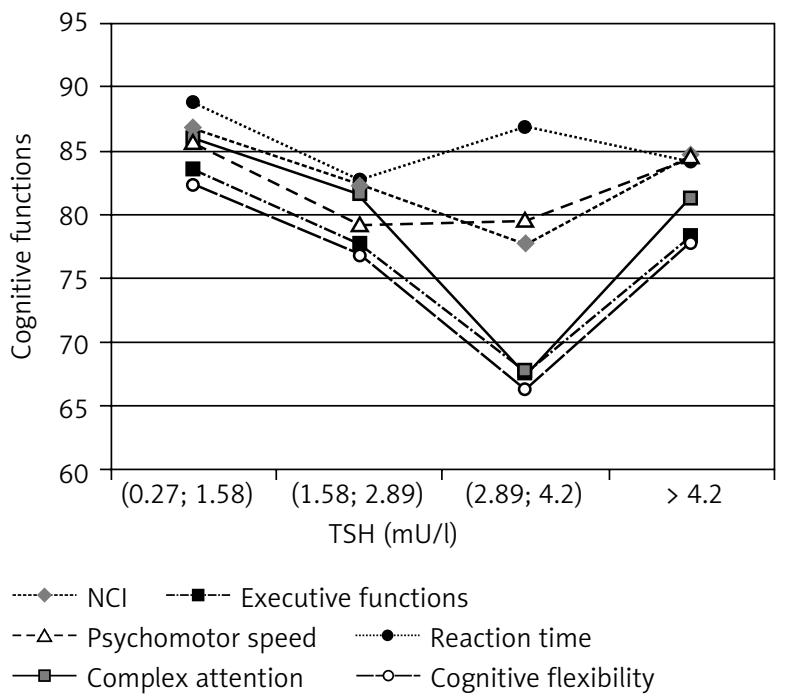

Fig. 1. Cognitive functions according to the TSH standards

Tab. I. Cognitive functions (standardized scores) according to the TSH norms

\begin{tabular}{|c|c|c|c|c|c|c|c|c|c|c|}
\hline \multirow[t]{2}{*}{ Domain } & \multicolumn{2}{|c|}{ Low standard } & \multicolumn{2}{|c|}{ Middle standard } & \multicolumn{2}{|c|}{ High standard } & \multicolumn{2}{|c|}{ Above standard } & \multicolumn{2}{|c|}{ Significance of differences } \\
\hline & M & SD & M & SD & M & SD & M & SD & $F$ & $p$ \\
\hline $\mathrm{NCl}$ & 86.75 & 15.19 & 82.40 & 14.98 & 77.67 & 18.32 & 84.61 & 19.23 & 5.188 & 0.002 \\
\hline Memory & 90.90 & 14.89 & 90.33 & 17.30 & 86.61 & 16.42 & 90.52 & 15.09 & 1.100 & 0.349 \\
\hline Verbal memory & 91.58 & 18.28 & 90.26 & 17.76 & 90.26 & 17.52 & 92.77 & 14.53 & 0.238 & 0.870 \\
\hline Visual memory & 94.36 & 13.53 & 93.65 & 18.02 & 89.19 & 16.02 & 92.84 & 14.64 & 1.748 & 0.157 \\
\hline Processing speed & 79.69 & 13.90 & 78.19 & 16.09 & 78.00 & 14.41 & 81.00 & 13.13 & 0.497 & 0.685 \\
\hline Executive functions & 83.63 & 24.12 & 77.74 & 22.93 & 67.69 & 27.18 & 78.35 & 26.87 & 6.377 & 0.000 \\
\hline Psychomotor speed & 85.68 & 15.63 & 79.33 & 20.40 & 79.57 & 20.33 & 84.42 & 21.66 & 3.382 & 0.018 \\
\hline Reaction time & 88.71 & 16.15 & 82.76 & 16.97 & 86.87 & 17.37 & 84.19 & 17.56 & 2.762 & 0.042 \\
\hline Complex attention & 86.20 & 26.50 & 81.69 & 25.83 & 67.43 & 33.13 & 81.26 & 33.95 & 6.513 & 0.000 \\
\hline Cognitive flexibility & 82.40 & 25.29 & 76.88 & 23.96 & 66.26 & 28.07 & 77.90 & 27.21 & 5.931 & 0.001 \\
\hline
\end{tabular}


Tab. II. Cognitive functions (standardized scores) according to the FT3 standards

\begin{tabular}{lcccccc}
\hline \multirow{2}{*}{ Domain } & \multicolumn{2}{c}{ Low standard } & \multicolumn{2}{c}{ Middle or high standard } & \multicolumn{2}{c}{ Significance of differences } \\
\cline { 2 - 8 } & $\mathbf{M}$ & SD & M & SD & $t$ & $p$ \\
\hline $\mathrm{NCl}$ & 84.53 & 14.92 & 85.59 & 18.10 & 0.597 & 0.551 \\
\hline Memory & 90.67 & 15.48 & 89.20 & 16.21 & 0.847 & 0.398 \\
\hline Verbal memory & 90.93 & 17.84 & 92.00 & 17.88 & 0.543 & 0.588 \\
\hline Visual memory & 94.43 & 15.25 & 91.23 & 14.59 & 1.935 & 0.054 \\
\hline Processing speed & 79.24 & 14.23 & 79.45 & 14.86 & 0.132 & 0.895 \\
\hline Executive functions & 79.50 & 24.51 & 82.02 & 24.93 & 0.929 & 0.354 \\
\hline Psychomotor speed & 82.41 & 18.78 & 86.85 & 15.64 & 2.259 & 0.024 \\
\hline Reaction time & 86.43 & 16.49 & 88.29 & 17.07 & 1.011 & 0.313 \\
\hline Complex attention & 82.33 & 27.30 & 84.14 & 29.48 & 0.584 & 0.559 \\
\hline Cognitive flexibility & 78.49 & 25.43 & 80.51 & 26.71 & 0.711 & 0.478 \\
\hline
\end{tabular}

$\mathrm{NCl}$ - Neurocognitive Index

psychomotor speed (84.42 points on average), complex attention (81.26 points on average), as well as poor assessment of executive functions (78.35 points on average) and cognitive flexibility (77.90 points on average).

Subjects with a level of TSH within the lower limit of the normal range had better reaction time (88.71 points on average, or evaluation below the average) than subjects with TSH in the middle standard (82.76 points on average) and above the norm (84.19 points on average). Also, subjects with the TSH level in the middle standard obtained lower results of these functions than those with TSH in the high range of the norm (86.87 points on average).

The analysis of the results of $\mathrm{NCl}$ and cognitive functions (in points) in the tested women depending on the level of FT3, located in the low, middle or high standards, revealed significant differences in psychomotor speed. The women who had low-normal FT3 obtained poorer results in psychomotor speed compared to the subjects with the middle and high standards (82.41 vs. 86.85 points on average) (Table II).

The analysis of the results of $\mathrm{NCl}$ and cognitive functions (in points) of the tested women depending on the level of FT4 below the standards and in the three standard intervals, showed significant differences in psychomotor speed. The subjects with the level of FT4 below standard achieved significantly lower scores in this function (76.60 points on average, or poor assessment) compared to the women with the middle (87.42 points on average) and low FT4 stand-

Tab. III. Cognitive functions (standardized scores) according to the FT4 standards

\begin{tabular}{|c|c|c|c|c|c|c|c|c|c|c|}
\hline \multirow[t]{2}{*}{ Domain } & \multicolumn{2}{|c|}{ Below standard } & \multicolumn{2}{|c|}{ Low standard } & \multicolumn{2}{|c|}{ Middle standard } & \multicolumn{2}{|c|}{ High standard } & \multicolumn{2}{|c|}{ Significance of differences } \\
\hline & $M$ & SD & $M$ & SD & $M$ & SD & M & SD & $F$ & $p$ \\
\hline $\mathrm{NCl}$ & 84.30 & 11.94 & 82.97 & 18.39 & 86.29 & 14.35 & 86.89 & 14.43 & 1.250 & 0.291 \\
\hline Memory & 88.16 & 14.62 & 90.10 & 16.46 & 91.34 & 15.16 & 88.42 & 13.17 & 0.571 & 0.634 \\
\hline Verbal memory & 88.14 & 14.81 & 90.78 & 18.11 & 93.75 & 18.13 & 85.89 & 15.68 & 1.993 & 0.115 \\
\hline Visual memory & 92.93 & 17.89 & 93.94 & 14.61 & 92.47 & 15.13 & 96.58 & 11.53 & 0.547 & 0.651 \\
\hline Processing speed & 80.86 & 11.74 & 77.41 & 14.27 & 80.81 & 14.29 & 82.63 & 19.41 & 2.078 & 0.103 \\
\hline Executive functions & 82.79 & 21.20 & 78.27 & 26.86 & 80.65 & 23.29 & 82.95 & 28.82 & 0.578 & 0.630 \\
\hline Psychomotor speed & 76.60 & 19.89 & 82.14 & 19.48 & 87.42 & 14.77 & 83.05 & 16.97 & 4.734 & 0.003 \\
\hline Reaction time & 85.21 & 13.27 & 85.37 & 17.38 & 89.63 & 16.27 & 88.58 & 15.61 & 1.993 & 0.115 \\
\hline Complex attention & 87.65 & 23.66 & 79.02 & 31.83 & 84.58 & 24.83 & 85.79 & 31.75 & 1.678 & 0.171 \\
\hline Cognitive flexibility & 81.79 & 22.72 & 76.82 & 28.21 & 79.91 & 23.61 & 81.89 & 29.92 & 0.704 & 0.550 \\
\hline
\end{tabular}


ards (82.14 points on average), who scored below the average (Table III).

Furthermore, it was checked whether there were significant differences between the results of $\mathrm{NCl}$ and cognitive functions (in points), and the levels of TT3 and TT4 in the low, middle and high standards. There were significant differences in memory and psychomotor speed depending on the TT3 in the low, middle and high standards (Table IV).

Women with the TT3 level located in the low standard had better results in these functions (the average memory scores were at the level of 91.48 points, and psychomotor speed at 84.91 points) compared to the women in the middle or high TT3 standards (the average memory scores amounted to 88.03 points, and psychomotor speed to 80.74 points). In contrast, no sig- nificant differences were found in $\mathrm{NCl}$ and the cognitive functions depending on TT4 in the two compartments' standards (Table V).

The analysis of the relationship between $\mathrm{NCl}$, cognitive functions (in points) and the normative and nonnormative anti-TPO results revealed significant differences in verbal memory, visual memory, processing speed and reaction time (Table $\mathrm{VI}$ ).

The subjects with anti-TPO levels in the middle standard achieved better verbal memory performance (94.57 points on average, or the average assessment) compared to the women with anti-TPO in the low norm (the average scores of verbal memory amounted to 88.83 points) and those above the standard (88.96 points on average). These two groups of women received results below the average in the evaluation of this function.

Tab. IV. Cognitive functions (standardized scores) according to the TT3 standards

\begin{tabular}{|c|c|c|c|c|c|c|}
\hline \multirow[t]{2}{*}{ Domain } & \multicolumn{2}{|c|}{ Low standard } & \multicolumn{2}{|c|}{ Middle or high standard } & \multicolumn{2}{|c|}{ Significance of differences } \\
\hline & $M$ & SD & $M$ & SD & $t$ & $p$ \\
\hline $\mathrm{NCl}$ & 85.14 & 15.40 & 83.09 & 17.34 & 1.202 & 0.230 \\
\hline Memory & 91.48 & 14.66 & 88.03 & 16.95 & 2.099 & 0.036 \\
\hline Verbal memory & 92.47 & 17.39 & 89.52 & 18.30 & 1.588 & 0.113 \\
\hline Visual memory & 93.94 & 14.79 & 92.09 & 15.53 & 1.166 & 0.244 \\
\hline Processing speed & 80.21 & 15.41 & 78.20 & 13.00 & 1.326 & 0.186 \\
\hline Executive functions & 79.83 & 24.49 & 79.34 & 25.97 & 0.187 & 0.852 \\
\hline Psychomotor speed & 84.91 & 17.20 & 80.74 & 19.07 & 2.211 & 0.028 \\
\hline Reaction time & 86.93 & 16.11 & 86.31 & 17.87 & 0.354 & 0.723 \\
\hline Complex attention & 83.53 & 26.85 & 80.59 & 31.15 & 0.975 & 0.330 \\
\hline Cognitive flexibility & 79.08 & 25.13 & 77.81 & 27.46 & 0.467 & 0.641 \\
\hline
\end{tabular}

$\mathrm{NCl}$ - Neurocognitive Index

Tab. V. Cognitive functions (standardized scores) according to the TT4 standards

\begin{tabular}{|c|c|c|c|c|c|c|}
\hline \multirow[t]{2}{*}{ Domain } & \multicolumn{2}{|c|}{ Low standard } & \multicolumn{2}{|c|}{ Middle or high standard } & \multicolumn{2}{|c|}{ Significance of differences } \\
\hline & $M$ & SD & $M$ & SD & $t$ & $p$ \\
\hline $\mathrm{NCl}$ & 84.71 & 16.03 & 83.56 & 16.91 & 0.649 & 0.517 \\
\hline Memory & 90.59 & 15.97 & 89.15 & 15.27 & 0.847 & 0.398 \\
\hline Verbal memory & 91.19 & 17.62 & 90.98 & 18.28 & 0.107 & 0.915 \\
\hline Visual memory & 94.00 & 15.89 & 92.23 & 13.28 & 1.092 & 0.276 \\
\hline Processing speed & 78.67 & 14.90 & 80.27 & 13.46 & 1.029 & 0.304 \\
\hline Executive functions & 80.52 & 24.92 & 77.63 & 25.68 & 1.064 & 0.288 \\
\hline Psychomotor speed & 83.68 & 17.69 & 83.17 & 18.85 & 0.263 & 0.793 \\
\hline Reaction time & 86.73 & 15.33 & 86.99 & 19.31 & 0.143 & 0.886 \\
\hline Complex attention & 81.80 & 29.35 & 82.40 & 27.86 & 0.192 & 0.848 \\
\hline Cognitive flexibility & 79.46 & 25.86 & 76.42 & 26.85 & 1.074 & 0.284 \\
\hline
\end{tabular}

$\mathrm{NCl}$ - Neurocognitive Index 
Tab. VI. Cognitive functions (standardized scores) according to the Anti-TPO standards

\begin{tabular}{lcccccccccc}
\hline \multirow{2}{*}{ Domain } & \multicolumn{2}{c}{ Low standard } & \multicolumn{2}{c}{ Middle standard } & \multicolumn{2}{c}{ High standard } & \multicolumn{2}{c}{ Above standard } & \multicolumn{2}{c}{ Significance of differences } \\
\cline { 2 - 14 } & M & SD & M & SD & M & SD & M & SD & $F$ & $p$ \\
\hline NCl & 84.18 & 15.80 & 85.86 & 16.67 & 82.50 & 14.89 & 83.27 & 16.68 & 0.653 & 0.582 \\
\hline Memory & 90.42 & 15.31 & 91.72 & 14.70 & 91.63 & 13.96 & 87.09 & 17.58 & 1.763 & 0.154 \\
\hline Verbal memory & 88.83 & 18.79 & 94.57 & 14.73 & 93.50 & 18.54 & 88.96 & 19.31 & 3.065 & 0.028 \\
\hline Visual memory & 96.36 & 11.72 & 92.65 & 16.02 & 93.07 & 14.85 & 90.46 & 16.99 & 2.986 & 0.031 \\
\hline Processing speed & 77.19 & 15.91 & 82.06 & 12.43 & 82.63 & 9.27 & 76.96 & 15.29 & 4.011 & 0.008 \\
\hline Executive functions & 80.37 & 24.63 & 81.60 & 26.11 & 73.67 & 25.83 & 78.26 & 23.93 & 0.967 & 0.408 \\
\hline Psychomotor speed & 84.16 & 16.96 & 83.56 & 18.48 & 82.53 & 18.74 & 82.53 & 18.95 & 0.171 & 0.916 \\
\hline Reaction time & 83.71 & 16.92 & 88.25 & 15.83 & 91.60 & 18.75 & 87.66 & 16.56 & 2.710 & 0.045 \\
\hline Complex attention & 84.21 & 26.01 & 84.19 & 29.96 & 78.03 & 26.24 & 78.18 & 30.63 & 1.251 & 0.291 \\
\hline Cognitive flexibility & 79.11 & 25.57 & 80.27 & 27.87 & 73.50 & 24.38 & 77.34 & 24.76 & 0.651 & 0.582 \\
\hline NCl - Neurocognitive Index & & & & & & & & & &
\end{tabular}

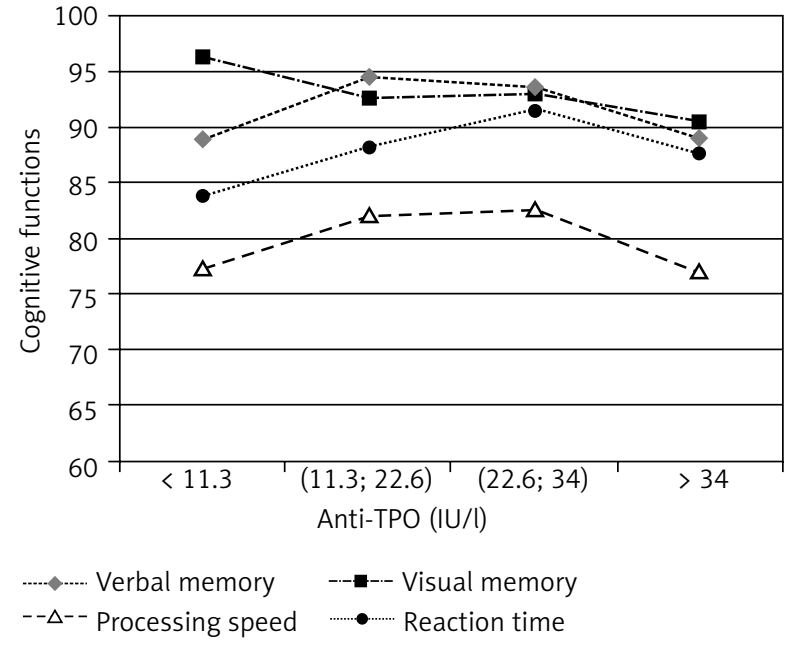

Fig. 2. Cognitive functions according to the Anti-TPO standards

As for visual memory, women with anti-TPO in the low norm (96.36 points on average) obtained better results compared to subjects in the middle anti-TPO standard (92.65 points on average) and above the norm (90.46 points on average).

In terms of processing speed, women with antiTPO in the middle standard (82.06 points on average, or assessment below the average) achieved significantly better results compared to women in the low norm (77.19 points on average) and above the standard (76.96 points). These two groups of women had poor evaluation in the function.

The results of reaction time were significantly lower in subjects with levels of anti-TPO in the low norm (83.71 points on average) compared to the sample in the middle (88.25 points on average) and high standards (91.60 points on average).
The normal level of AB-TSHR or above the standard significantly differentiated the results of $\mathrm{NCl}$, processing speed, executive functions, psychomotor speed, complex attention and cognitive flexibility (Table VII).

Subjects with the AB-TSHR levels in the low or middle standards had significantly better results of $\mathrm{NCl}$, executive functions, psychomotor speed, complex attention and cognitive flexibility (the average values were: 86.59 ; 84.76; 85.81; 87.91; 83.52 points, respectively, or assessment below the average) compared with women whose levels of AB-TSHR were above the norm (the average values were: $81.92 ; 75.20 ; 80.50 ; 77.14 ; 73.86$ points, respectively, or mostly poor evaluation), and these women, in turn, had significantly lower scores in $\mathrm{NCl}$ and the listed features than women with the high AB-TSHR standard (the average values: 85.69; 81.45; 84.94; 84.09; 80.66 points, respectively).

Another relationship was found in the results of processing speed. The subjects with AB-TSHR above the norm had better results (the average value was 82.27 points, i.e. the assessment was below the average) than those with AB-TSHR located in the low or middle standards (77.01 points on average) and the high standard (77.43 points on average). These two groups of women received poor evaluation in the function.

\section{Discussion}

Other researchers have shown that deviation from thyroid hormone levels may be a risk factor for Alzheimer's disease [10]. It was found that low levels, but within the normal range, of thyroxine were associated with a higher risk of cognitive impairment during the three years of observation in older women [11].

Authors have also dealt with the relationship between subclinical thyroid disease, variations in the thy- 
Tab. VII. Cognitive functions (standardized scores) according to the AB-TSHR standards

\begin{tabular}{|c|c|c|c|c|c|c|c|c|}
\hline \multirow[t]{2}{*}{ Domain } & \multicolumn{2}{|c|}{ Low or middle standard } & \multicolumn{2}{|c|}{ High standard } & \multicolumn{2}{|c|}{ Above standard } & \multicolumn{2}{|c|}{ Significance of differences } \\
\hline & $M$ & SD & $M$ & SD & $M$ & SD & $F$ & $p$ \\
\hline $\mathrm{NCl}$ & 86.59 & 16.99 & 85.69 & 15.48 & 81.92 & 16.24 & 3.074 & 0.047 \\
\hline Memory & 90.91 & 14.55 & 90.89 & 15.77 & 89.01 & 16.19 & 0.671 & 0.512 \\
\hline Verbal memory & 90.14 & 19.24 & 92.69 & 17.69 & 90.52 & 16.87 & 0.763 & 0.467 \\
\hline Visual memory & 95.53 & 12.86 & 92.78 & 15.41 & 92.61 & 15.84 & 1.241 & 0.290 \\
\hline Processing speed & 77.01 & 17.45 & 77.43 & 12.85 & 82.27 & 13.13 & 5.737 & 0.004 \\
\hline Executive functions & 84.76 & 23.38 & 81.45 & 24.66 & 75.20 & 25.82 & 4.732 & 0.009 \\
\hline Psychomotor speed & 85.81 & 16.53 & 84.94 & 15.78 & 80.59 & 20.51 & 3.192 & 0.042 \\
\hline Reaction time & 86.79 & 14.41 & 87.37 & 16.53 & 86.46 & 18.21 & 0.109 & 0.897 \\
\hline Complex attention & 87.91 & 24.99 & 84.09 & 27.96 & 77.14 & 30.57 & 4.571 & 0.011 \\
\hline Cognitive flexibility & 83.52 & 25.33 & 80.66 & 25.26 & 73.86 & 26.64 & 4.658 & 0.010 \\
\hline
\end{tabular}

$\mathrm{NCl}$ - Neurocognitive Index

roid function within the normal range, and impaired cognitive function in healthy adults and patients with dementia. Several studies, including those conducted in the elderly, reported that subclinical hypothyroidism (normal FT4 with elevated TSH) was associated with an impaired cognitive function in elderly patients [12-14]. Other studies suggest that differences in total thyroxine within the normal range are positively related to the general cognitive function in healthy elderly people [15], while elevated FT4 levels may worsen the cognitive deficits and cause depression in patients with Alzheimer's disease [16].

The studies also revealed that postmenopausal women had significant differences in $\mathrm{NCl}$, executive functions, psychomotor speed, reaction time, complex attention and cognitive flexibility, depending on normative (in three intervals of the norm) and non-normative TSH levels. The women in the low TSH standard had better results in $\mathrm{NCl}$, executive functions, psychomotor speed, complex attention and cognitive flexibility compared to the women in the high standard. The subjects with TSH in the lower limit of the norm had better response time than those with TSH in the middle of the norm and above. Also, subjects with TSH in the middle range of the standard had lower results in this function than subjects with TSH in the high range of the norm.

Women with low-normal FT3 obtained poorer results in psychomotor speed compared to subjects with the middle or high standards. Subjects with levels of FT4 below the standard achieved significantly lower scores in this function compared to women with FT4 within the middle and low standards.

Women with TT3 levels within the low norm had better memory and psychomotor speed compared to women with the middle or high TT3 standards.

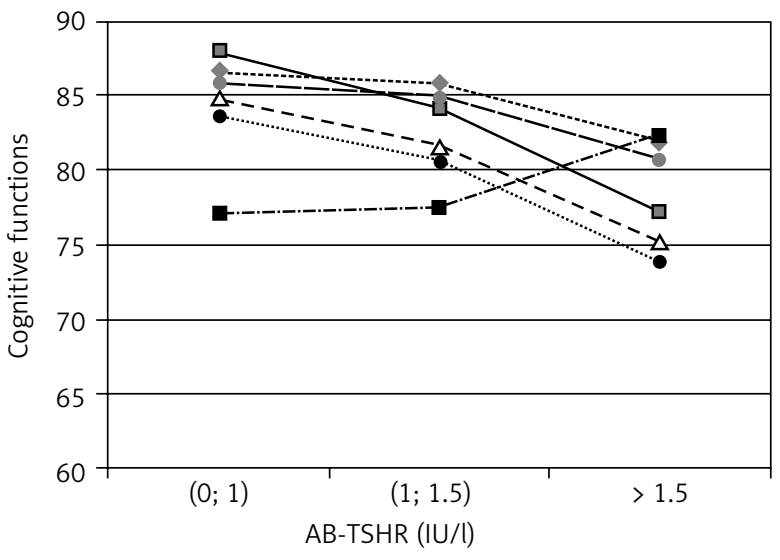

$-\mathrm{NCl} \quad---$ Processing speed -- $-\Delta-$ Executive functions -........ Psychomotor speed $\quad \square-$ Complex attention

Fig. 3. Cognitive functions according to the AB-TSHR standards

The authors of other studies, which were aimed to assess the presence of possible significant differences in cognition in elderly patients affected by subclinical hypothyroidism, have noted that patients with this thyroid disorder had considerably lower MMSE scores compared with euthyroid individuals [17]. Another report showed a group of 425 patients aged from 65 to 85 years with a weakening of verbal memory in subclinical hypothyroidism [18].

Similar results with respect to TSH were obtained by Hogervorst et al. in a study on a group of 1,047 people aged 64 years. During two years of observation, the authors found that high levels of TSH positively correlated with poorer results of MMSE, regardless of the level of FT4, gender, education or mood. Other results of studies on FT4 noted that high normal FT4 positively correlated with worse outcomes in MMSE, and a reduction 
by at least 4 points in the test result within two years of observation. The authors suggest the need for thyroid function tests in older people with handicapped cognitive functions. They cannot, however, explain why high normal FT4 values positively correlated with accelerated cognitive decline [19].

Other authors present the results of a meta-analysis based on 23 studies. The evaluation included the relationship between subclinical hyperthyroidism or low levels of TSH and cognitive functions. Based on fourteen properly designed studies they displayed the relationship between subclinical hyperthyroidism and cognitive impairment or dementia. According to the authors, there is a large amount of evidence on the relationship between subclinical hyperthyroidism and cognitive impairment, but there is no proof that anti-thyroid treatment may alleviate the symptoms of dementia [20].

However, one of the latest reports on a study conducted in a group of 5154 men and women aged 70-82 years without previously diagnosed thyroid dysfunction, examined cognitive functions using five neuropsychological tests, at baseline and at four consecutive time points during a follow-up of 3 years. It showed no differences between the results of cognitive tests in subclinical hyperthyroidism and hypothyroidism compared to the outcomes obtained by euthyroid individuals [21].

Subjects with levels of anti-TPO in the middle standard achieved better results in verbal memory and processing speed compared to women with the anti-TPO concentration in the low standard and those above the norm. As for visual memory and reaction time, women with the low anti-TPO standard obtained better results compared to the subjects in the middle anti-TPO norm and above the standard.

Subjects with levels of AB-TSHR in the low or middle norms had significantly better results in $\mathrm{NCl}$, executive functions, psychomotor speed, complex attention and cognitive flexibility compared to women with AB-TSHR levels above the norm. In turn, they obtained considerably lower scores in $\mathrm{NCl}$ and the listed features than the women with the high AB-TSHR standard. Another relationship was found in the results of processing speed. In contrast, subjects with AB-TSHR levels above standard were better in processing speed than subjects with the AB-TSHR value located in the low, middle or high standards.

Like the previously-quoted study conducted by Grigorova et al., our work evaluated the effect of the autoantibodies level on cognitive functions. It was found that the higher concentrations of anti-thyroglobulin antibodies positively correlated with more errors in the Trail Making Test Part B, Word Fluency test, and Design Fluency test. The authors suggest that higher levels of FT3 and TgAb, but within the normal range, may adversely affect executive functions, but this was not observed in our study [22].
In order to confirm the relationship between thyroid dysfunction and the results of cognitive tests, changes in these functions after the treatment are also worth mentioning. In particular, the treatment of hypothyroidism, including the subclinical form, can bring benefits in terms of cognition, which was confirmed in the literature.

The studies have shown that patients with hypothyroidism and memory disorders achieved an improvement in this area after treatment with L-thyroxine [23, 24]. A possibility to reverse some aspects of cognitive disorders was demonstrated, especially in hypothyroidism, after the use of L-thyroxine. Bono et al. [25] reported a small but significant improvement in verbal fluidity in women with subclinical hypothyroidism after 6 months of treatment, but the study failed to prove a correlation between the changes in TSH and treatment. The study conducted by del Ser Quijano et al. showed that treatment with L-thyroxine significantly improved multiple cognitive functions, including complex attention, memory, verbal fluidity and executive functions, in comparison with the control group [26]. A recent, randomized, placebo-controlled study evaluating the effects of L-thyroxine on the cognitive function, however, did not confirm the hopes of preventing unfavorable changes in cognition through the treatment of thyroid dysfunction at the sub-clinical level. The analysis of data from the MMSE test, Middlesex Elderly Assessment of Mental State test, and Trail-Making test revealed that there was no conclusive evidence that the treatment of elderly patients with subclinical hypothyroidism using L-thyroxine improved their cognitive functions [27].

\section{Conclusions}

The concentrations of the tested laboratory parameters of the thyroid functional status located within the upper limits of the normal range showed a different relationship with cognitive performance than the concentrations within the lower limits of the normal range.

\section{Disclosure}

Authors report no conflicts of interest.

\section{References}

1. Jabłkowska K, Karbownik-Lewińska M, Nowakowska K, et al. Pamięć operacyjna i funkcje wykonawcze w nadczynności tarczycy w przebiegu choroby Gravesa i Basedowa. Psychiatria Polska 2008; 42: 249-259.

2. Ben-Skowronek I, Wisniowiecka M. Replacement therapy of secondary hypothyroidism in children born with low body weight improves mental development. Ann Agric Environ Med 2012; 19: 567-571.

3. Derkacz M, Michałojć-Derkacz M, Chmiel-Perzyńska I, et al. Zaburzenia psychiczne a nadczynność tarczycy. Curr Probl Psychiatry 2011; 12: 146-151. 
4. Suwalska A, Łojko D. Zaburzenia psychiczne w chorobach endokrynnych i ich leczenie. Terapia 2004; 12: 25-29.

5. Dąbkowska M, Augustyńska B, Odrowąż-Sypniewska G, et al. Poziom hormonu tyreotropowego a wybrane funkcje poznawcze $u$ chorych na schizofrenię. Postępy Psychiatrii i Neurologii 2008; 17: 29-33.

6. Borkowska A, Junik R. Zaburzenia funkcji poznawczych w nadczynności tarczycy. Psychiatr Pol 2007; 41 supl 3: 13.

7. Mason GA, Walker $\mathrm{CH}$, Prange AJ. L-triiodothyronine: is this peripheral hormone a central neurotransmitter. Neuropsychpharmacol 1993; 3 253-258.

8. Magierska J, Magierski R, Fendler W, et al. Clinical application of the Polish adaptation of the Montreal Cognitive Assessment (MoCA) test in screening for cognitive impairment. Neurol Neurochir Pol 2012; 46 130-139.

9. Gualtieri CT, Johnson LG. Reliability and validity of a computerized neurocognitive test battery, CNS Vital-Signs. Arch Clin Neuropsychol 2006 21: 623-643.

10. Kalmijn S, Mehta KM, Pols HA, et al. Subclinical hyperthyroidism and the risk of dementia. The Rotterdam study. Clin Endocrinol (Oxf) 2000; 53: 733-737.

11. Volpato S, Guralnik JM, Fried LP, et al. Serum thyroxine level and cognitive decline in euthyroid older women. Neurology 2002; 58: 1055-1061.

12. Baldini IM, Vita A, Mauri MC, et al. Psychopathological and cognitive features in subclinical hypothyroidism. Prog Neuropsychopharmaco Biol Psychiatry 1997; 21: 925-935.

13. Osterweil D, Syndulko K, Cohen SN, et al. Cognitive function in nondemented older adults with hypothyroidism. J Am Geriatr Soc 1992 40: 325-335

14. Wahlin A, Backman L, Mantyla T, et al. Prior knowledge and face recognition in a community-based sample of healthy, very old adults. J Geronotol 1993; 48: 54-61.

15. Prinz PN, Scanlan JM, Vitaliano PP, et al. Thyroid hormones: positive relationships with cognition in healthy, euthyroid older men. J Geronto A Biol Sci Med Sci 1999; 54: M111-M116.

16. Stuerenburg HJ, Arlt S, Mueller-Thomsen T. Free thyroxine, cognitive decline and depression in Alzheimer's disease. Neuro Endocrinol Lett 2006; 27: 535-537.
17. Cook SE, Nebes RD, Halligan EM, et al. Memory impairment in elderly individuals with mildly elevated serum $\mathrm{TSH}$ : the role of processing resources, depression and cerebrovascular disease. Aging 2002; 9: $175-$ 183.

18. Manciet G, Dartigues JF, Decamps A. The PAQUID survey and correlates of subclinical hypothyroidism in elderly community residents in the southwest of France. Age Aging 1995; 24: 235-241.

19. Hogervorst E, Huppert F, Matthews FE, et al. Thyroid function and cognitive declinein the MRC Cognitive Function and Ageing Study. Psychoneuroendocrinol 2008; 33: 1013-1022.

20. Gan EH, Pearce SH. Clinical reviev: The thyroid in mind: cognitive function and low thyrotropin in older people. J Clin Endocrinol Metab 2012; 97: 3438-3449.

21. Wijsman LW, de Craen AJ, Trompet S, et al. Subclinical thyroid dysfunction and cognitive decline in old age. PLoS One 2013; 8: e59199.

22. Grigorova M, Shervin BB. Thyroid hormones and cognitive functioning in healthy, euthyroid women: a correlational study. Horm Behav 2012; 61: 617-622.

23. Capet $C$, Jego A, Denis $P$, et al. Is cognitive change related to hypothyroidism reversible with replacement theraphy? La Revue de Medicine Interne 2000; 21: 672-678.

24. Jensovsky J, Ruzicka E, Spackova N, et al. Changes of event related potential and cognitive process in patients with subclinical hypothyroidism after thyroxine treatment. Endocrin Regul 2002; 36: 115-122.

25. Bono G, Fancellu R, Blandini F, et al. Cognitive and affective status in mild hypothyroidism and interaction with L-thyroxine treatment. Acta Neurol Scand 2004; 110: 59-66.

26. del Ser Quijano T, Delgado C, Martìnez Espinosa S, et al. Cognitive deficiency in mild hypothyroidism. Neurologia 2000; 15: 193-198.

27. Parle J, Roberts L, Wilson S, et al. A randomized controlled trial of the effect of thyroxine replacement on cognitive function in community-living elderly subject with subclinical hypothyroidism: the Birmingham elderly thyroid study. J Clin Endocrinol Metab 2010; 8: 3623-3632. 